\title{
Exploring lecturer engagement with the VLE: findings from a multi-college staff survey
}

\author{
Tom Farrelly, Institute of Technology Tralee \\ Damien Raftery, Institute of Technology Carlow \\ Nuala Harding, Athlone Institute of Technology
}

\begin{abstract}
Virtual Learning Environments (VLEs) are important infrastructure and digital educational spaces that are widely used. The lecturers' voices on VLEs and their use were not adequately captured in the \#VLEIreland project. Therefore, following the development and piloting of a questionnaire consisting of a common set of questions, lecturers were surveyed across seven Irish higher education institutes. There were 580 responses from staff who use the VLE, with the analysis based upon the 521 valid responses. The findings will explore the VLE features or tools used by lecturers, their attitude to the VLE, and barriers to the use of the VLE and related issues, including that of intellectual property ownership. Lecturers are broadly positive about VLEs, with 7 in 10 of those who use the VLE strongly agreeing that it is helpful. However the adoption and use of VLEs is not without difficulties. In particular, time pressures emerged as barriers to use, limiting the use of VLEs and engagement with training. Despite this, $91 \%$ of respondents answered Yes to the question "Are you interested in making more use of online tools in your teaching?" Drawing on the issues highlighted in the findings, this paper will explore the attitudes of lecturers to the VLE and the enablers of, and inhibitors to, their greater engagement with the VLE.
\end{abstract}

\section{Introduction}

The need to develop academics' digital capacity and digital pedagogical knowledge has been identified as a strategic goal at national (National Forum, 2015; National Forum, 2016) and EU level (European Commission, 2014; OECD, 2012). The OU Innovating Pedagogy report (Sharples et al., 2015) emphasizes changes in pedagogical approaches afforded by technology, with Daniel (2016) suggesting that online learning should be treated as the default, rather than face-to-face classroom teaching.

O'Rourke (2017), in a review of infrastructure of Irish higher education institutions, states that "all Irish institutions report usage of the VLE by in excess of $80 \%$ of academic staff" (p.14). However, Devine (2015) commented that Irish higher education lacks an evidence base in relation to VLE usage (p.16).

Irish Journal of Technology Enhanced Learning Ireland, 2018. (C) 2018 Farrelly, T., Raftery, D. \& Harding, N. The Irish Journal of Technology Enhanced Learning Ireland is the journal of the Irish Learning Technology Association, an Irish-based professional and scholarly society and membership organisation. (CRO\# 520231) http://www.ilta.ie/. This is an Open Access article distributed under the terms of the Creative Commons Attribution 4.0 International License (http://creativecommons.org/licenses/by/4.0), allowing third parties to copy and redistribute the material in any medium or format and to remix, transform, and build upon the material for any purpose, even commercially, provided the original work is properly cited and states its license. 
The \#VLEIreland longitudinal student surveys have provided valuable insights into the students' use of, and attitudes to VLEs (Raftery \& Risquez, 2018; Ryan \& Risquez, 2018). The VLE staff survey was developed to, as well as giving individual institutions useful information, increase knowledge around lecturers' use of, and attitudes to, the VLE. Following a summary of research methods, this article presents and discusses an analysis of academic staff's views on the use of VLEs across higher education in Ireland. In particular, we focus our analysis on the 521 responses from staff in seven Irish higher education institutions who reported using VLEs. The basis for this article stems from conference papers (Farrelly et al., 2015 and 2016) and we would like to acknowledge the valuable contributions of all our collaborators in the development of the survey, and for collecting and sharing data. Prior to conclusions, the findings are discussed along with other research and some implications are drawn.

\section{Methods}

To get a greater insight into the views of lecturers, and to complement the ongoing surveys of students, in 2014 a common questionnaire to be used across multiple institutions was developed. Questions were designed to survey lecturers on their uses and views of VLEs and, more broadly, technology to enhance learning. The questionnaire evolved from a previous version that was pilot tested in one college in 2011 and another in 2013, mirroring to a good extent the student version.

The online survey was carried out in December 2014 and February/March 2015. In each college, invitations were emailed to staff inviting them to participate by completing the survey on SurveyMonkey (www.surveymonkey.com). 580 responses were received. The response rates in the seven colleges varied and, as the survey was administered online, the sample is self-selecting leading to potential sample bias. Thus a note of caution when interpreting the results of the survey is that those who did not respond may differ from those who did; in particular the respondents may be disproportionately drawn from the ranks of those who are positively predisposed towards technology. In this article, percentages are calculated out of those who responded to the question.

The analysis below focuses on the 521 who had used the VLE. The proportion of respondents from the seven institutions is: $24 \%, 17 \%, 17 \%, 14 \%, 12 \%, 9 \%$ and $8 \%$ respectively. Of the 521 respondents, 280 use one particular VLE, with the remaining 241 using another VLE. Of those who stated their sex, $55 \%$ were female ( $45 \%$ male); for age, $3.8 \%$ were age $21-30,25 \%$ $31-40,44 \% 41-50,26 \% 51-60$ with $1.8 \%$ over 60 years.

\section{Findings}

The findings are presented in three thematic sections. Section 3.1 highlights the range of VLE features/tools used by lecturers and highlights issues regarding the use of VLEs as a teaching platform. In section 3.2 we move onto an examination the lecturers' attitudes to the use of VLEs, with section 3.3 focusing on the barriers to use.

\subsection{VLE features/tools used by lecturers}

Although VLEs have a wide range of features; as Figure 1 indicates it is the content repository and communication features that were by far the most popular ways in which 
VLEs are employed, followed by assessment management. In fact, there is almost universal use of the VLE to share learning resources, the advantages of which are noted by this lecturer who states that:

It is useful for storing material when teaching on several different courses, seeing if students are using it, maintaining contact with students when they are on placements, providing additional resources for students who may need particular support. It gives students greater flexibility about when they read material, students can share resources on it which gives a great sense of learning as a co-operative endeavour.

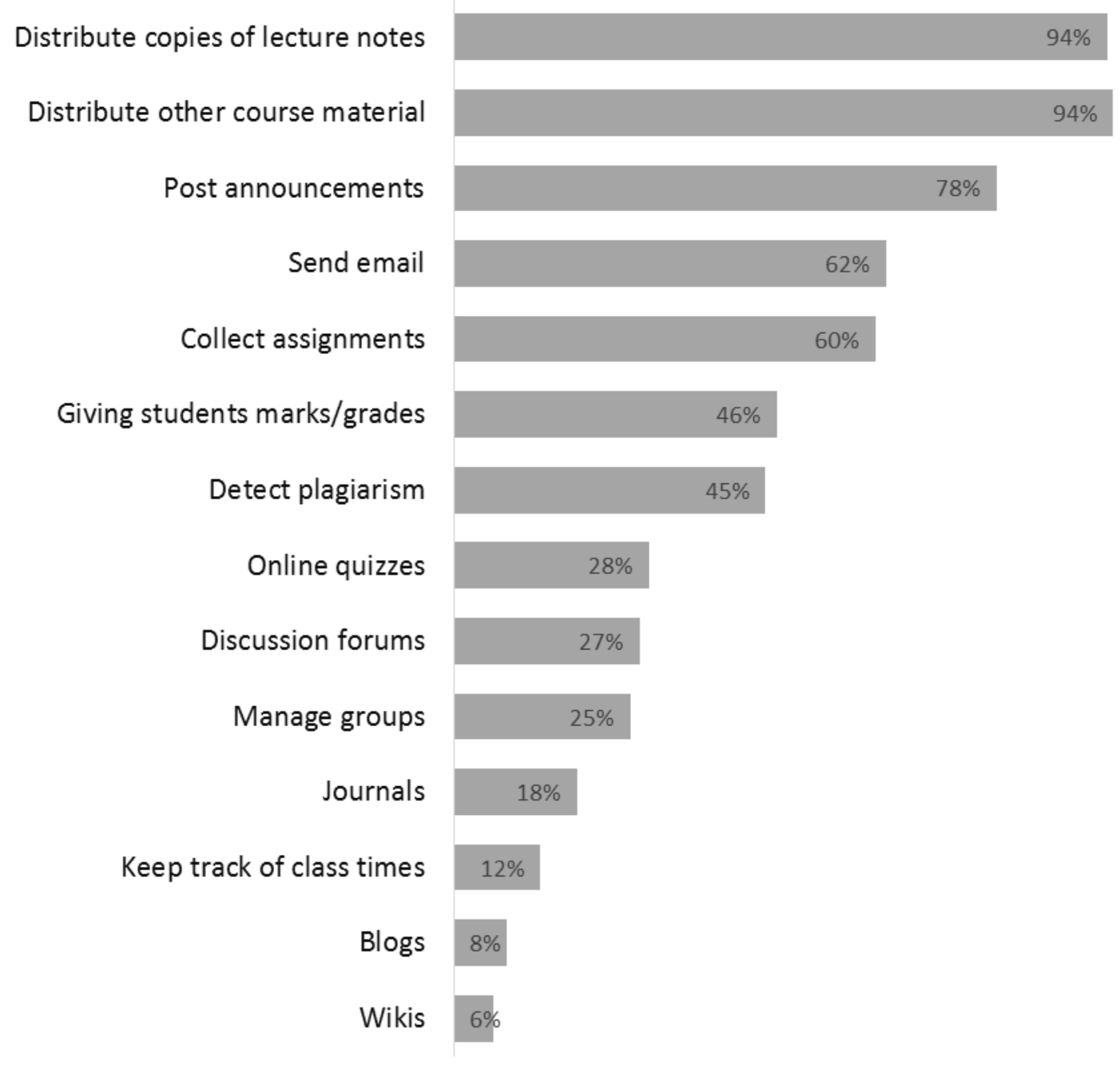

Figure 1: Proportion of lecturers rating VLE features Very Useful or Useful - VLEs used more than just a repository for lecture notes and other course material

Figure 1 certainly highlights the fact that VLEs in this instance are overwhelmingly used as remote content repositories. There is also extensive use of assignment management collection of assignments, checking for text copied from other sources and giving students marks. Although other features (or tools) are lagging in use, there is still substantial use of online quizzes and discussion forums with some use to manage groups and of journals. 


\begin{tabular}{lrrr} 
& $\begin{array}{l}\text { Yes, } \\
\text { within } \\
\text { [VLE] }\end{array}$ & $\begin{array}{l}\text { Yes, } \\
\text { outside } \\
\text { [VLE] }\end{array}$ & $\begin{array}{l}\text { No, } \\
\text { do } \text { not } \\
\text { use }\end{array}$ \\
\hline Assignment submission & 318 & 67 & 109 \\
Plagiarism detection (using Turnitin/SafeAssign) & 239 & 62 & 186 \\
Access to external web based resources or digital repositories & 223 & 130 & 143 \\
\hline Videos and screencasts & 157 & 108 & 223 \\
Online assignment feedback (using Turnitin/SafeAssign/Inline Grading) & 146 & 46 & 280 \\
Asynchronous Collaborative tools (discussion boards, blogs, wikis, ...) & 113 & 47 & 320 \\
Online quizzes (formative, for feedback) & 108 & 48 & 330 \\
Audio/Video Lecture recordings & 106 & 81 & 291 \\
Online quizzes (summative, for marks) & 96 & 29 & 357 \\
\hline Online journal tool & 59 & 34 & 379 \\
Online student presentations (individual and group) & 45 & 71 & 352 \\
Podcasts & 44 & 65 & 358 \\
Synchronous Collaborative tools (virtual classroom, Skype etc) & 37 & 63 & 368 \\
e-portfolio/PDP/progress files & 27 & 37 & 403 \\
Peer assessment tools & 22 & 61 & 383 \\
Simulations and games & 15 & 55 & 391 \\
\hline
\end{tabular}

Table 1: Online tools and techniques reported as used in the previous twelve months

The tools and techniques utilized, while indicating a wide variety of uses would indicate a tendency towards supporting the management of learning rather than student learning itself. For example as Table 1 indicates: three of the top five tools are associated with assignment management and feedback. A classification of the open-ended responses to the question "Are there any other ways, good or bad, that using [VLE] affects your teaching?" highlighted the ease of sharing materials with students (42 respondents), the convenience to students (23 respondents) and to lecturers (23 respondents), and the help the VLE provides to the lecturer to be organised (18 respondents). The following quote is quite indicative of the positive responses with regard to assignment submission and management features: "Using Turnitin Feedback helps give feedback to large numbers. Submissions never get lost. So assessment is more streamlined."

\subsection{Lecturer attitudes to the VLE}

Lecturers were posed with a number of statements that examined attitudes regarding issues such as ease of use, reliability and the lecturer's perception of the benefit to students of VLE use. However, large scale quantitative responses can only paint part of the overall picture, consequently a number of the open-ended responses are included by way of illustration and balance.

As Figure 2 indicates, lecturers are in broad agreement that VLEs are helpful for their students. 


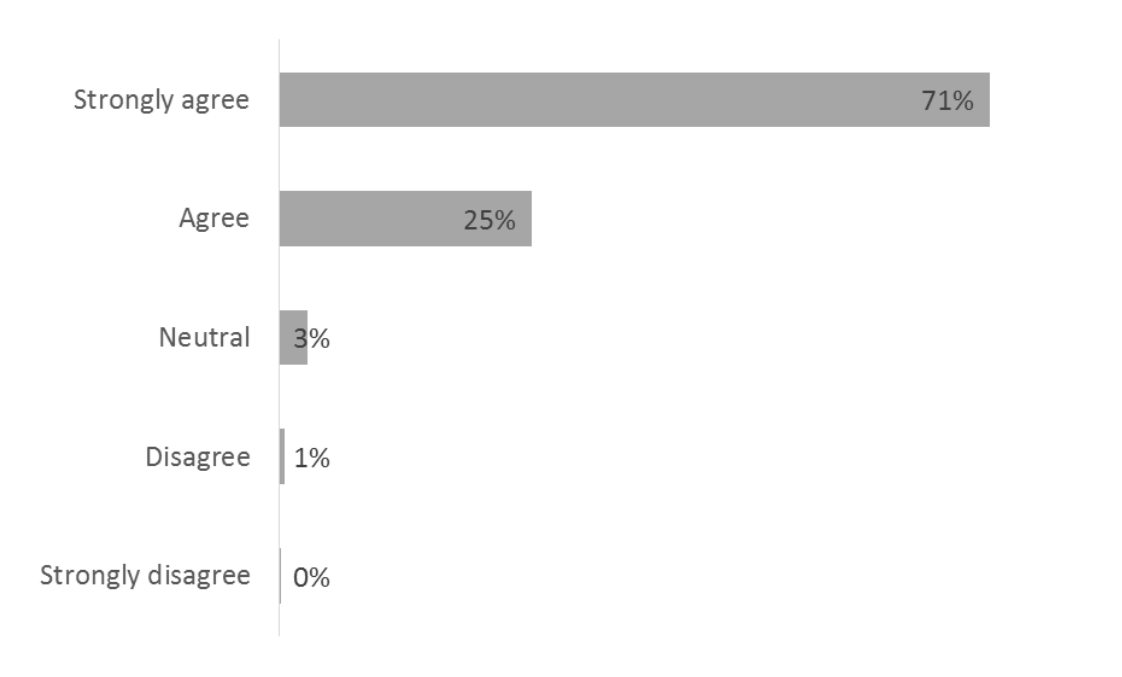

\section{Figure 2: 96\% of lecturers think systems like the VLE are helpful}

However, even with such an overwhelmingly positive response rate, a number of respondents suggested that the use of VLEs is not always beneficial as illustrated by the following quotes:

I do not think VLE adds anything to teaching. It has a number of course administration and student tracking benefits. Teaching happens in the classroom.

Very large numbers of students limit meaningful engagement with VLE, e.g. Forum Discussions.

Limitations for learners too, i.e. around the issues of digital inclusion especially second chance learners.

Nothing, because it's a commercial technology in search of a use, not a legitimate pedagogical tool. People who use it - and people who promote its use - are being suckered by powerful companies with product to sell. I'm no sucker.

Given the general increase in class sizes across many HEIs, one of the stated advantages of VLEs is that they provide the lecturer with another avenue to access and interact with their students. As Figure 3 indicates, although $70 \%(n=357)$ of those who responded to this question indicated the VLE provides more access to students, only $7 \%(\mathrm{n}=37)$ disagreed or strongly disagreed with this statement. 


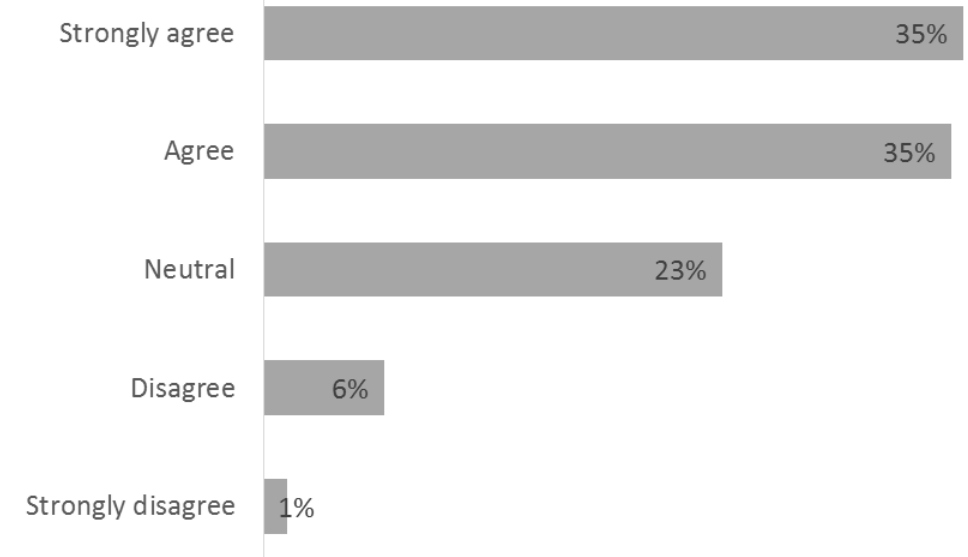

Figure 3: 70\% of lecturers agree that using the VLE gives me more access to my students

When asked to rate ease of use, $70 \%(\mathrm{n}=361)$ of the respondents either agreed or strongly agree that their VLE was easy to use. That said, that still leaves $30 \%(n=153)$ who are either neutral or disagree as illustrated by the following quote: "[VLE] could be more user friendly - it is a bit clunky (for editing purposes and copying)."

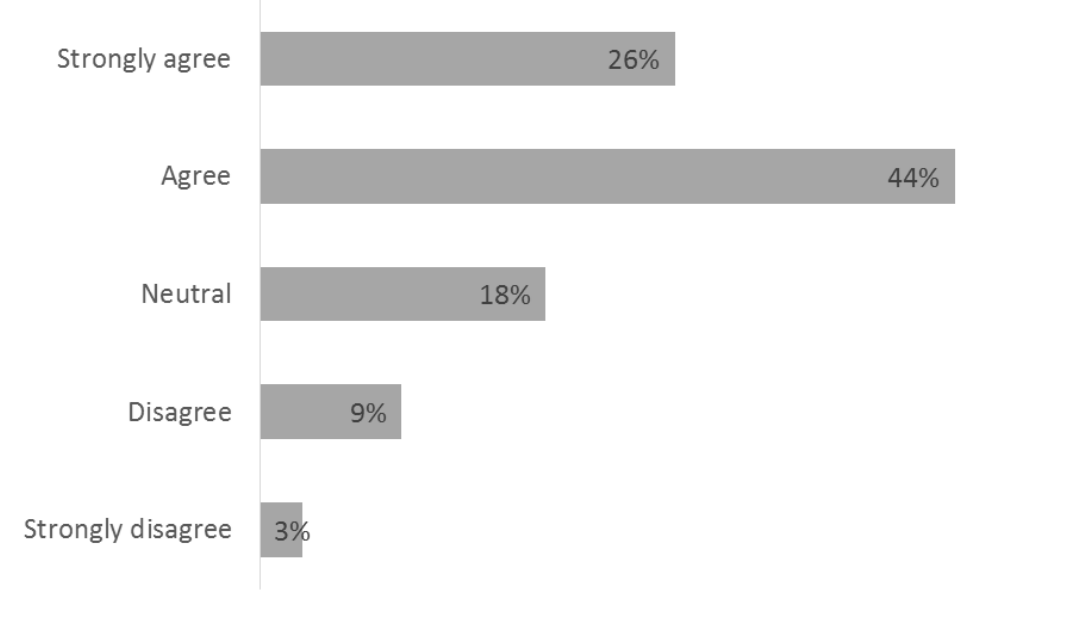

\section{Figure 4: 70\% of lecturers think the VLE is easy to use}

Another issue closely related to the issue of user acceptance is that of reliability. VLE platforms - regardless of their range of functionality, the lecturer's preference or ease of use - are only effective if users feel comfortable using the technology and assured that it will do what they want when they want. As figure 5 indicates $80 \%(n=408)$ of those who responded to this question think their VLE is reliable, with $6 \%(\mathrm{n}=31)$ disagreeing. 


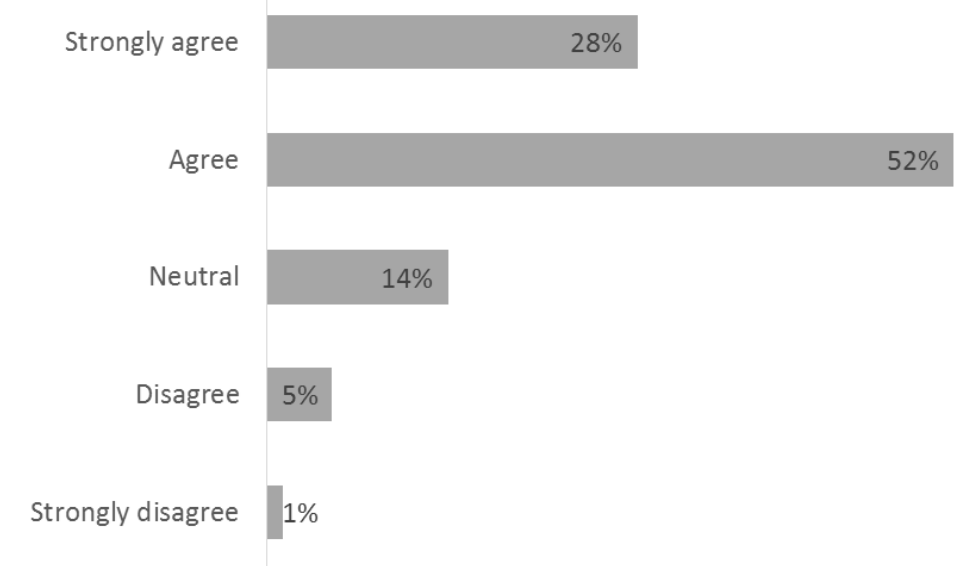

\section{Figure 5: 80\% of lecturers agree the VLE is reliable}

While a majority report that their VLE is reliable, there are a number issues regarding the provision of adequate help and support. Taken together, figures 6 and 7 are highly informative. For example, while $70 \%(n=358)$ in figure 6 agree that they can get adequate support, $60 \%(n=286)$ in figure 7 report that they do not have sufficient time to learn how to use their VLE. In fact, one of the major themes to emerge from the study is that of time poverty on the part of lecturers. This includes: time to attend training, time to master the new techniques and time to effectively teach using the range of tools within the VLE.

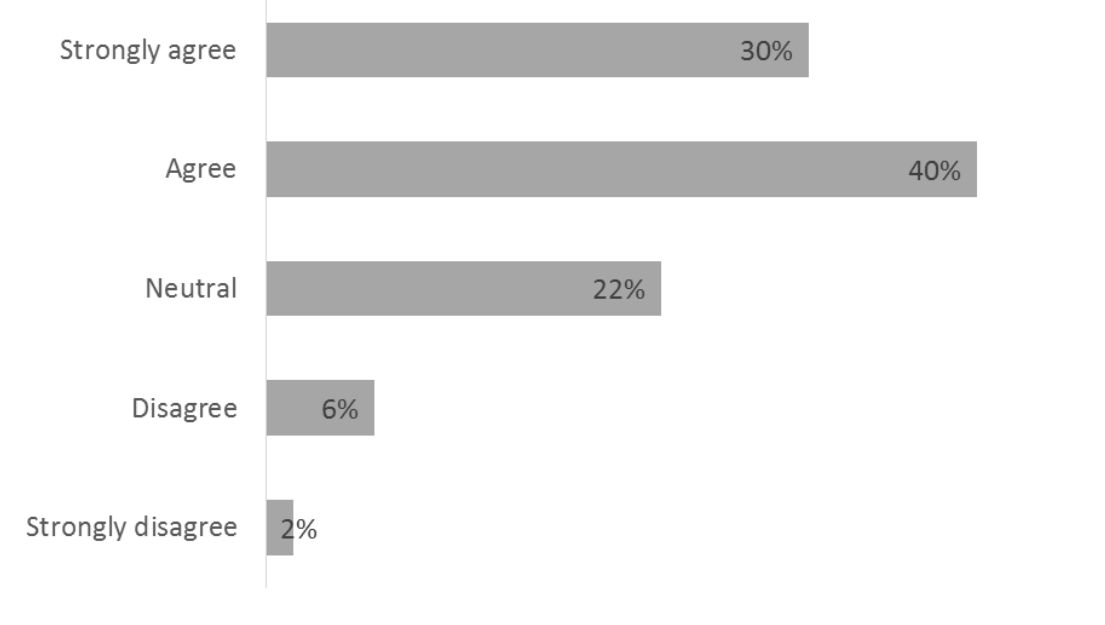

Figure 6: 70\% of lecturers agree they can get adequate help and support to use VLE 


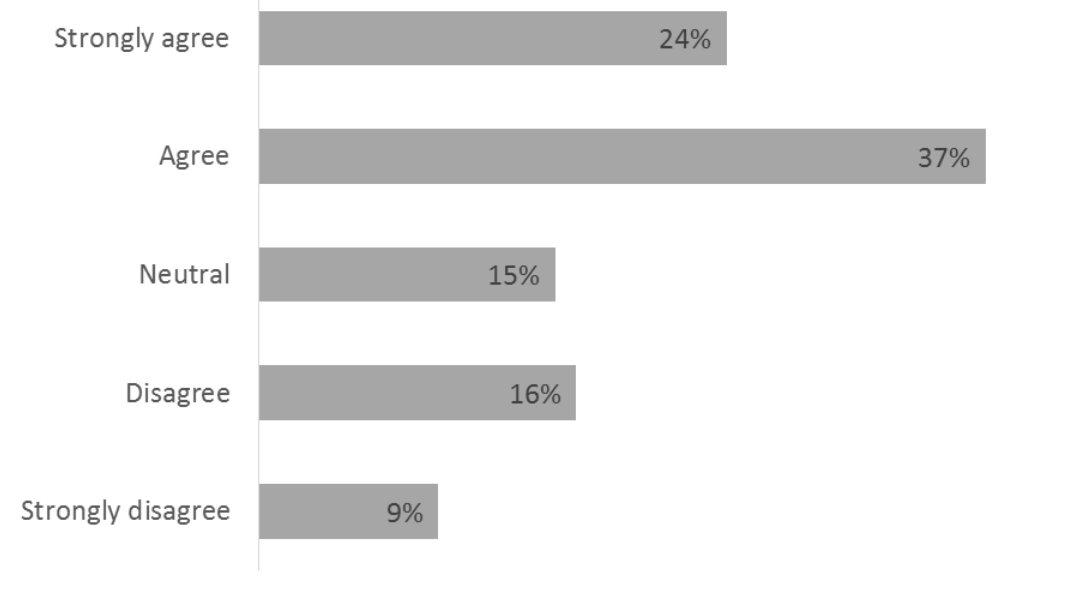

\section{Figure 7: 60\% of lecturers agree they don't have time to learn how to use VLE or other} online tools

In terms of formal training in the use of the VLE, 176 respondents indicated they had attended training workshops; 54 have attended a basic introduction and 32 availed of one-toone training. The responses to the statement: "Training is available but not suited to my requirements", returned the following: $39 \%(n=177)$ of lecturers disagreed with the statement with $32 \%(n=147)$ neutral and $29 \%(n=133)$ agreeing, so there may be some scope to widen and improve the training options available.

\subsection{Barriers and issues}

An analysis of the open-ended responses to the question "Is there anything that prevents you from getting best use of the VLE?" supports the above focus on lack of time (stated by 135 respondents) and need for more or better training (64 respondents). Other issues emerging from the comments centred on usability problems of VLEs ( 80 respondents) and technical issues (53 respondents).

A further classification of the open-ended responses to the question "Are there any other reasons you choose not to, or are prevented from, making use of online tools in your teaching?" again highlighted time pressures ( 77 respondents), with some identifying a need for more training (30 respondents) and needing to know more about the VLE (16 respondents). A small number commented that the VLE was not suitable for their teaching (13 respondents).

Issues identified in the open-ended responses included students over-reliance on the VLE (41 respondents), the potential impact of the VLE on attendance (30 respondents), technical issues (25 respondents) and possible passivity of students (15 respondents). However, it is worth noting that there is a degree of debate as to the benefits of providing course material in advance of lectures. For example, $27 \%$ indicated concern that the online provision of lecture notes will affect attendance at lectures, with $24 \%$ neutral and $49 \%$ disagreeing. Copyright and intellectual property (IP) ownership were another set of issues highlighted in the open responses as illustrated by this comment: "Lack of control over the material when it is published ... materials are used and abused elsewhere online, so why bother putting it up on [VLE] to be stolen by others?". While such fears are of course understandable the survey also 
highlights that copyright and IP cuts both ways. For example, one of the open ended questions asked: How do you deal with copyright issues for digital learning objects that you reuse? Over 380 responses were coded producing a wide range of categories; the top ten categories are illustrated in table 2 . While it is clear that the vast majority of respondents utilise some form of acknowledgement system it is worth noting that over 60 respondents either do not know the rules or do not think about the issue.

\begin{tabular}{lr} 
Code & $\begin{array}{r}\text { Number of } \\
\text { references }\end{array}$ \\
\hline Use references (e.g. reference secondary sources on handouts or PPT slides) & 77 \\
Use other acknowledgement of source & 44 \\
Don't/I do not think about it & 42 \\
I don't know the rules & 19 \\
Ignore it & 17 \\
Use Creative Commons materials & 16 \\
Seek and/or get permission to use something & 16 \\
Fair use/rely on permitted use for teaching & 16 \\
Inclusion of a link on teaching materials & 18 \\
I use publicly available material & 10 \\
\hline
\end{tabular}

\section{Table 2: Copyright acknowledgement}

Despite time pressures and other issues identified above, $91 \%$ of respondents answered Yes to the question "Are you interested in making more use of online tools in your teaching?" However, as previously acknowledged, these participants are staff who generally use VLEs to some extent and as a consequence there is the potential for self-selection bias.

\section{Discussion}

Higher education institutions (HEIs) are being encouraged to respond to the challenge of the changing economic and social conditions with a call to be more creative, innovative and inclusive in their teaching and learning strategies. The National Strategy for Higher Education to 2030 (DES, 2011) highlighted the need to "respond positively to the continuing professional development needs of the wider community to develop and deliver appropriate modules and programmes in a flexible and responsive way" (p.79) and the need for "open distance e-learning and work-based learning" (p.103). In theory VLEs provide a very useful tool that help meet these needs.

There is little doubt that VLEs offer lecturers, their institutions and their students the potential to create an engaging learning environment that can facilitate learning remotely and/or support existing traditional class based courses. As previously noted, the VLEs are primarily used for content management and communication. While there is nothing wrong in itself with just providing course material, one could argue that this can be done far cheaper and easier without recourse to having an expensive VLE. This point about using VLEs to undertake features available (for free) on other platforms was well made by Martin Weller's (2007) often cited 'The VLE/LMS Is Dead'. We are not here to debate in whether the VLE is dead or dying except to note that judging by the responses, VLEs are still in some form of rude health and show no sign of imminent death. Given the likely traditional face-to-face nature of programmes taught by the lecturers surveyed, with the VLE mostly being used to enhance the student experience whilst retaining an emphasis on classes, it is unsurprising that 
all of the tools of the VLE are not used extensively - rather there is an emphasis on those features and tools that support the teaching of face-to-face classes. This may change as more strongly blended approaches are adopted.

Returning to the findings, a number of questions have been raised: what is the purpose of VLEs? How are they being used by lecturers? And, what do institutions need to do to support lecturers use VLEs (effectively)?

From an institutional perspective the main advantages of using VLEs reportedly are: flexibility of time and space, coping with increased student numbers, sharing and re-using of resources, collaborative work and reduction of the administrative burden (O'Rourke, Rooney, \& Boylan, 2015). However, assumptions that ICTs in education would reduce costs, especially the costs of expensive human resources, such as teachers/tutors have proved to be somewhat wide of the mark. VLEs can provide a range of learning opportunities that might otherwise not be easily available, but consideration needs to be given to the provision of a realistic level of resources if they are to be educationally meaningful and effective.

As the findings indicated, one of the most pressing issues surrounding the use of VLEs by lecturers was that of time, or more accurately, the lack of it. It is evident that an appropriate allocation of time is needed to train lecturers how to use the technology effectively and then the time needed to monitor the VLE and maintain a social and cognitive 'presence' (Pelz, 2004; Donaldson, 2014). If meaningful online learning environments are to be maintained, sufficient thought needs to be given to how lecturers manage these environments. The issue of support is a particularly important aspect regarding lecturer use of VLEs. Because no matter how 'intuitive and user friendly the learning platform is, it is not realistic to expect tutors to be able to use it without substantial training and support' (Powell \& Minshull, 2004, p.14). The comment regarding the management of large discussion groups is a case in point. While a lecturer may wish to create an interactive online environment that utilizes a wide range of the VLE's tools; the reality of managing large classes without a sufficient time allocation may inhibit choice. In such instances, it is easy to appreciate that the VLE may revert to simply being a content repository with the lecturer choosing a more didactic and restrictive approach to the scope of the VLE's uses.

One of the key features regarding technology acceptance is the issue of ease of use (Kurt \& Tingöy, 2017). Figure 2 highlighted the responses in relation to reported ease of use with $70 \%$ agreeing that their VLE is easy to use. That said, for such an important aspect of VLE usage that still leaves $30 \%$ who either disagree or are undecided. If VLEs are not intuitive and easy to navigate, particularly if lecturers wish to use a wider range of a VLE's tools the level of usage is likely to remain low and within a narrow confine of possible roles.

There is little point in presenting VLEs as a self-evident good and hope that they will be seamlessly implemented within the operations of HEIs without serious consideration being given to the issues that need to be addressed and resolved (see Harding (2018) in this issue for further discussion of staff development). For example, as the earlier quote regarding the ownership of material indicated there are (amongst some lecturers) concerns regarding copyright and intellectual property ownership. The point about intellectual property (IP) ownership as a possible dissuading factor has been previously highlighted (McMahon, 2016) and as such needs to be given further consideration and clarity if IP is to be removed as a possible impediment to greater VLE usage by lecturers. It would appear that there is a wide disparity amongst HEIs with regard to the archiving of course material on VLEs. While this 
was not explicitly investigated in this iteration of the study, consideration will be given to this issue in future staff surveys.

\section{Conclusion}

While we acknowledge the potential for self-selection bias of the sample, we suggest that this research does give room for some degree of optimism. As previously discussed, there is often the assumption that VLEs are simply used as remote content repositories. While the findings do indeed indicate their use as a means of distributing content there is strong evidence to suggest that a number of the communication features are being employed such as announcements, email features and discussion forums. These, combined with the use of the VLE to manage the submission and grading of assignments and some use of online quizzes, suggest that VLEs are being used to create learning environments as well as a means of content distribution. However, this is the high point of optimism. Conversely, the utilization of VLEs across the HE sector would suggest a patchwork approach with little evidence of wholesale acceptance and even less certainty about the role and purpose of VLEs.

HEIs need to create environments that are conducive to employing innovative ICT strategies 'where pedagogical and curriculum concerns drive technological developments rather than vice versa' (Hannon, 2005, p.975). It is almost as if colleges are saying: 'we have this expensive product, should we not use it, rather than saying how can we offer a different type of learning experience using new technologies?' (ibid., p.975). Institutions need to give consideration to both how they will use VLEs and support the use VLEs if they are to create a genuine learning environment and not to be simply a remote content repository. VLEs seem to offer a useful platform whereby content, teaching and learning can be married into one meaningful alternative learning environment; and not just an environment regarded as supplemental to traditional learning. However, VLE platforms exist within a milieu that is reliant on issues such as connectivity, technical support and training, user experience and abilities, all of which impact on their potential effectiveness. Notwithstanding these issues, it is evident that the extent and nature of VLE use of by academic staff is the key to the enhancement of the student learning experience on the VLE. 


\section{References}

Daniel, J. S. (2016). Making Sense of Blended Learning: Treasuring an Older Tradition or Finding a Better Future? [online], TeachOnline.ca. Retrieved from:

http://teachonline.ca/tools-trends/blended-learning-successful-design-delivery-and-studentengagement/making-sense-blended-learning-treasuring-older-tradition-or-finding-betterfuture.

Devine, J. (2015). Strategic and Leadership Perspectives on Digital Capacity in Irish Higher Education. Dublin: National Forum for the Enhancement of Teaching and Learning. Retrieved from: https://www.teachingandlearning.ie/wp-content/uploads/2014/03/SeniorManagement-FINAL.pdf

Department of Education and Skills (DES) (2011). National Strategy for Higher Education to 2030 - Report of the Strategy Group. Dublin: Government Publications.

Donaldson, L. (2014). Integrating Web 2.0 Learning Technologies in Higher Education: The Necessity, The Barriers and The Factors for Success. All Ireland Journal of Teaching and Learning in Higher Education, 6(3), pp. 1-22, Retrieved from http://ojs.aishe.org/index.php/aishe-j/article/view/202/293

European Commission (2014) Report to the European Commission on New Modes of Learning and Teaching in Higher Education, High Level Group on the Modernisation of Higher Education. Retrieved from:

http://ec.europa.eu/education/library/reports/modernisation-universities_en.pdf.

Farrelly, T., Raftery, D., Harding, N., Risquez, A., O’Grady, M., McAvinia, C., Costello, E., Ryan, D., McSweeney, D., \& Logan-Phelan, T. (2016). VLEs - What Lecturers Want and Do. EdTech 2016, Law Society, Dublin, 26th-27th May 2016.

Farrelly, T., Raftery, D., Risquez, A., McAvinia, C., Harding, N., Costello, E., O'Grady, M., Ryan, D., McSweeney, D., \& Logan-Phelan, T. (2015). Exploring lecturer engagement with the VLE: initial findings from a multi-college survey. EdTech 2015, University of Limerick, 28th-29th May 2015.

Hannan, A. (2005). Innovating in higher education: contexts for change in learning technology. British Journal of Educational Technology, 36(6), 975-985

Harding, N. (2018): The Digital Turn: staff perceptions of the virtual learning environment and the implications for educational developers. [Special Issue, McAvinia and Risquez]. Irish Journal of Technology Enhanced Learning, 3(2), 58-76

Kurt, O. E. \& Tingöy, O. (2017). The acceptance and use of a virtual learning environment in higher education: an empirical study in Turkey, and the UK. International Journal of Educational Technology in Higher Education, 14(36). Retrieved from https://link.springer.com/article/10.1186/s41239-017-0064-Z 
McMahon, M. J. (2016). The Adoption of a Virtual Learning Environment Among "Digital Immigrant" Engineering Lecturers: a Case Study. Irish Journal of Academic Practice, 5(1). Retrieved from http://arrow.dit.ie/ijap/vol5/iss 1/3

OECD (2012). Fostering quality teaching in higher education: Policies and Practices. An IMHE Guide for Higher Education Institutions. Retrieved from:

http://www.oecd.org/edu/imhe/qt\%20policies\%20and\%20practices.pdf

O'Rourke, K. C. (2017). Ireland's Higher Education Technical Infrastructure: A review of current context, with implications for teaching, and learning enhancement. Dublin: National Forum for the Enhancement of Teaching and Learning. Retrieved from https://www.teachingandlearning.ie/wp-content/uploads/2017/12/Final-Infrastructure-reportwith-doi-web-ready.pdf

O'Rourke, K. C., Rooney, P., \& Boylan, F. (2015). What's the Use of a VLE? Irish Journal of Academic Practice, 4(1), 1-21. Retrieved from:

https://arrow.dit.ie/cgi/viewcontent.cgi?referer=https://www.google.ie/\&httpsredir=1\&article $=1043 \&$ context $=$ ijap

National Forum (2015). Teaching and Learning in Irish Higher Education: A Roadmap for Enhancement in a Digital World 2015-2017. Retrieved from:

http://www.teachingandlearning.ie/wp-content/uploads/2015/03/Digital-Roadmap-web.pdf.

National Forum (2016). National Professional Development Framework for All Staff Who

Teach in Higher Education. Retrieved from: https://www.teachingandlearning.ie/wpcontent/uploads/2016/09/PD-Framework-FINAL.pdf.

Pelz, B. (2004). (My) Three Principles of Effective Online Pedagogy. Journal of Asynchronous Learning Networks (JALN). 8(3). Retrieved from: https://www.ccri.edu/distancefaculty/pdfs/Online-Pedagogy-Pelz.pdf

Powell, B. \& Minshull, G. (2004). Choosing and using a learning platform in Adult and Community Learning. JISC/NIACE.

Raftery, D. \& Risquez, A. (2018). Engaging students through the VLE: comparing like with like using the \#VLEIreland student survey. [Special Issue, McAvinia \& Risquez]. Irish Journal of Technology Enhanced Learning, 3(2), 24-34.

Ryan, D. \& Risquez, A. (2018). 'Lessons Learnt': the student view in the \#VLEIreland project. [Special Issue, McAvinia \& Risquez]. Irish Journal of Technology Enhanced Learning, 3(2), 1-10.

Sharples, M., Adams, A., Alozie, N., Ferguson, R., Fitzgerald, E., Gaved, M., Mcandrew, P., Means, B., Remold, J., Rienties, B., Roschelle, J., Vogt, K., Whitelock, D., \& Yarnall, L. (2015). Innovating Pedagogy 2015: Open University Innovation Report 4. Milton Keynes: The Open University. Retrieved from: http://proxima.iet.open.ac.uk/public/innovating_pedagogy_2015.pdf.

Weller, M. (2007). The VLE/LMS Is Dead. Retrieved from http://nogoodreason.typepad.co.uk/no_good_reason/2007/11/the-vlelms-is-d.html 